\section{THE PRESIDENCY OF THE BOARD OF} EDUCATION.

THE office of President of the Board of Education has again become the shuttlecock of politics, pointedly illustrated by the remark so aptly made by a member of the House in the course of the important debate of July 18 on the introduction by Mr. Henderson of the Education Estimates, that "I have sat for eleven years in this House, and I have heard during that time no fewer than five Ministers make their statements on educational matters." It is thus that we are content to deal with the vital question of education. The circumstances of the war have forced home upon the attention of the least reflective of politicians the claims of the subject to the serious attention of the nation.

The course of the debate, in which members of very diverse political views participated, indicates that the time is fully ripe for a drastic review of the question in all its bearings. To do this effectively requires that there should be placed in control of the department, which should now take an equal place in the hierarchy of Government with the other great departments of the State alike in respect of the salary attached to it and of the dignity and responsibility in which it is held, a man of large and clear vision, of intimate knowledge, and of deep sympathy with the educational well-being of all classes of the people, and who is prepared with a single mind to devote all his time and thought to the consideration and solution of the serious problems which beset it. We have got as the most pressing need of the time to create in the English nation, as distinguished, say, from the Scotch, a genuine belief in the value of education as the true and only uplifting and sustaining force in the spiritual life and continued progress of the people. This can only have some chance of realisation in the event of the office of Secretary of State for Education-since that should be its rightful designation-being in the hands of such a man as is here described, who enjoys the confidence of the people and is prepared to regard the office, not as a stepping-stone or mere adjunct to some other, but as one demanding a continuity of thought and policy throughout the whole time his Government is in power. Such a Minister should be prepared, not merely from his place in Parliament, but from time to time in various great centres of population, to set forth his policy and to seek to arouse in the people by the enunciation of his ideals and by the methods of their realisation a great enthusiasm for education as the true foundation of the national salvation. It is not a question of a classical education versus an education in science, nor a question of industrial and commercial supremacy, nor of one class as distinguished from another, but of the right upbringing and development of all the children of the nation according to their gifts and capabilities. To a man of such distinction as is here foreshadowed would inevitably be committed a full inquiry under his presidency and with the aid not merely of officials, but also with that of the best available thought and ripe experience of every class, into the present conditions of education as exhibited throughout its entire range, from the kindergarten up to and including the university, with a view to its unification and to the establishment of a broad highway along which the gifted children of the nation might freely travel. This, as the course of the recent debate shows, is the psychological moment, and it should be seized with a firm hand. It will mean, as Mr. Henderson puts it, "money and more money." It will demand a higher and more attractive status for the teacher, with a clear avenue for the highest public service of which he is capable. But it will result that the coming generation of Englishmen will possibly be as receptive and as appreciative of the fruits of investigation, often enough due to the patience and genius of their own countrymen, as are the foreign enemies whose culture they hold in such disdain.

\section{EXPERIMENTS IN AERODYNAMICS. 1}

THE volume before us gives some of the first results obtained in the four-foot wind tunnel which has been erected at the Massâchusetts Institute of Technology, and consists of ten sections dealing with various phases of the work. The first section gives a detailed description of the wind tunnel, the design of which is practically identical with that of the four-foot tunnel at the National Physical Laboratory, Teddington. This is followed by a discussion of the dimensional theory as applied to aerodynamic problems. The theory is treated in a simple and easily followed manner, but due credit has not been given to Lord Rayleigh, who first proposed the theory in this form. Lord Rayleigh is mentioned, however, in this connection in a later section of the book. Section 3 deals with the inclined tube alcohol manometer for measuring small pressure differences. The results of the calibration of such an instrument against a standard Chattock manometer are given. The inclined tube instrument certainly has no advantages over the Chattock form, and experience at the National Physical Laboratory shows that the latter is exceedingly convenient for use. The theory of the pitot tube is considered, and experimental results are appended to show that several types of combined pitot and static pressure tubes give identical calibrations.

An interesting comparison with the National Physical Laboratory is given in the form of characteristic curves for the wing section known as R.A.F.6, and this comparison shows in a striking manner the accuracy of wind tunnel experiments. The results obtained in the two wind tunnels agree to the order of about 2 per cent., which is as good as the accuracy of manufacture of the models will allow.

The question of the steering of a dirigible is dealt with in one section of the volume, and the conclusion is drawn that it is almost out of the 1 "Beport on Wind Tunnel Experteriments in Aerodynamics." Smithsonian
Miscellaneous Collections, vol. lxis., No. .4*

NO. 2442, VOL. 97] 
question to put sufficient fin area on a dirigible to render it directionally stable, but that it may be controlled by comparatively small movements of the rudder. This conclusion is also in agreement with National Physical Laboratory results.

Section 8, on swept-back wings, and the following section on the effects of dihedral angle, are of considerable interest. The Dunne aeroplane has excited much interest, and great claims have been made for its stability. The results of the experiments in the American wind tunnel show that the effect of swept-back wings on longitudinal stability is nil, and that the degree of lateral stability due to a sweep back of $20^{\circ}$ is equally well obtained by a dihedral angle of only $22^{\circ}$, while the latter is much better from a constructional point of view.

The last section deals with the critical flow round flat discs normal to the wind. A mathematical investigation is given for the case of nonviscous irrotational motion, and it is shown that the results are of the same order as those of the experiments. The mathematical treatment is obviously inadequate, since it ignores just those qualities of the motion which affect its critical change of flow: the viscosity and the rotational motion. Similar problems have received attention at the National Physical Laboratory, and it is hoped to obtain, from actual photographs of the motion in special cases, some information which is not forthcoming from the hydrodynamical theory.

On the whole, the results given in the Smithsonian publication are very interesting and afford a useful independent comparison with those obtained in our own country at the National Physical Laboratory. The excellent agreement obtained in the general conclusions of the present volume with the previous work at the National Physical Laboratory leaves no possible doubt concerning the accuracy of experimental work of this description, or of the great utility of such experiments in helping forward the design of all kinds of aircraft.

E. F. R.

\section{GEOFFREY WATKINS SMITH.}

BY the death of Captain Geoffrey Watkins 13 Smith, of the Rifle Brigade, who was killed by a shell in France on July ro in a trench just taken from the enemy, zoological science loses one of the most promising and brilliant of its younger adherents, and his many friends have to regret a particularly lovable and gracious personality. Though only thirty-four years of age, Geoffrey Smith, by the abundance and originality of his researches, had won for himself a secure place in the scientific world, and his work was of such a nature that each step gave promise of further and more important discovery. It is not possible within the present limits of space to give more than a bare outline of his career and performance.

Geoffrey Smith, a son of Mr. Horace Smith, the well-known Metropolitan magistrate, was born at
Beckenham, Kent, on December 9, ı88ז. He was educated at Temple Grove, East Sheen, and afterwards at Winchester College, of which he was a scholar, and in due course obtained a scholarship at New College, Oxford. At Oxford, working under the late Prof. Weldon, he devoted himself to the studies for which he had already shown great aptitude in boyhood, and gained a first class in the Honour School of Natural Science in I903. He proceeded to the Zoological Station at Naples in the same year, and remained there till 1905 , when, having finished his monograph on the Rhizocephala, the only monograph in the Naples Fauna and Flora written by an Englishman, he returned to Oxford to take up the duties of demonstrator and lecturer in the University Museum. In 1906 he was elected fellow and tutor of New College in succession to Prof. G. C. Bourne, and remained at Oxford till October, 1914, except for an excursion to Tasmania in r907, the scientific results of which are published in a volume entitled "A Naturalist in Tasmania."

Geoffrey Smith's monograph on the Rhizocephala, an excellent piece of zoological research, has already been mentioned. As a result of his voyage to Tasmania he made several solid contributions to zoological science, publishing a memoir on the Anaspidacea, living and fossil, in rgog, and monographs on the fresh-water Crustacea of Tasmania and on the fresh-water Crayfishes of Australia in 1909 and rgr2. But his chief and most important work was his series of memoirs, eleven in number, on the experimental analysis of sex, issued from rgio to I9I4. In these essays, following up clues suggested to him by his work on the Rhizocephala, Geoffrey Smith attempted, and attempted successfully, to probe the physiological causes of the phenomena of secondary sexual characters. He showed that the assumption of female characters by the parasitised male crab Inachus is due to a profound change in metabolism induced by the parasitic Sacculina, and incidentally demonstrated that the facts proved that the male is heterozygous and the female homozygous for sex. By a masterly association of ideas he showed the close analogy between this physiological regulation in parasitised crabs and the phenomena of regulation which produce immunity in bacterial diseases. He extended his observations to bees, frogs, fowls, and pheasants, and successfully demonstrated similar physiological processes in these animals, at the same time bringing acute critical experimental work to bear on certain current theories of sex production.

Much had been achieved, but much was left unfinished when he accepted a commission in the New Armies in ror4. It is doubtful whether the work so brilliantly initiated can be carried on by any other hand, certainly not with the same prospect of success.

A final word must be said in praise of the elegance of Geoffrey Smith's literary style, and the grace, humour, and courtesy with which he was wont to deal with attacks upon his work.

No. 2442 , VOL. 97] 